\title{
Anesthesia in Patient with Shrinking Lung Syndrome: Case Report
}

\author{
Silvia Piccolo-Daher ${ }^{1}$, Edno Magalhães, TSA ${ }^{2}$
}

\begin{abstract}
Summary: Piccolo-Daher S, Magalhães E - Anesthesia in Patient with Shrinking Lung Syndrome: Case Report.
Background and objectives: The incidence of pulmonary involvement in systemic lupus erythematosus (SLE) may be presented as a syndrome called shrinking lung syndrome (SLS). SLS has quite a controversial pathophysiology, which can induce to a mechanical ventilation dependency. Due to its rarity, there is a limited number of publications on the subject. The objective of this report is to present the case of a patient with SLS who underwent incisional hernia repair under epidural anesthesia.
\end{abstract}

Case report: Female patient with SLE, hypertensive and obese, diagnosed with SLS 18 years ago. She was dependent on nocturnal oxygen at home, had dyspnea on minimal exertion and spirometry with severe restrictive ventilatory defect. In a previous post-operative period under general anesthesia, she remained on mechanical ventilation for 9 days with difficult weaning. She underwent incisional hernia repair for 3 hours under thoracic epidural anesthesia without any pre- or post-operative respiratory complication.

Conclusions: Shrinking lung syndrome is a rare disease that requires a prior knowledge of the clinical and laboratory history of the patient by the anesthesiologist. The thoracic epidural anesthesia technique proved to be a satisfactory option for this patient, with highly satisfactory respiratory evolution.

Keywords: Anesthesia, epidural; General Surgery; Lupus Erythematosus, systemic; Respiratory Muscles; Ventilation/complications.

\section{INTRODUCTION}

Systemic lupus erythematosus (SLE) is an autoimmune connective tissue disease, characterized by the formation of autoantibodies and immune complexes, with various clinical and immunological manifestations ${ }^{1}$. Pulmonary involvement can occur between $60 \%$ and $80 \%$ of the cases ${ }^{2}$, and may affect the upper airways, pleura, parenchyma and pulmonary vessels in different ways ${ }^{3}$. Some pleuropulmonary manifestations include pleuritis, pneumonitis, fibrosis, alveolar hemorrhage, bronchiolitis obliterans, hypertension, and pulmonary thromboembolism. More rarely, it may arise as the shrinking lung syndrome (SLS), a rare manifestation of SLE, characterized by unexplained dyspnea, restrictive pattern on spirometry, and elevation of the diaphragm, in the absence of parenchymal lung diseases ${ }^{4}$.

Received from Universidade de Brasília (UnB), Brazil.

1. Anesthesiologist

2. MSc; Associate Professor, Universidade de Brasilia (UnB); Scientific Director of the

Brazilian Society of Anesthesiology; Head of CET/SBA, UnB

Submitted on December 8, 2010

Approved on June 19, 2011

Correspondence to:

Dra. Silvia Piccolo Daher

SGAN 608, módulo $F$

Asa Norte

70850080 Brasília, DF, Brazil

E-mail: silviapd@gmail.com
Although there are some studies in literature describing the SLS, none of them consider the anesthetic management of these patients. The purpose of this report is to describe a case of a patient with SLS who underwent thoracic epidural anesthesia for incisional hernia repair.

\section{CASE REPORT}

Female patient, 54 years old, who underwent surgery for supraumbilical incisional hernia three months after a left adrenalectomy surgery (incidentaloma).

Diagnosed with rheumatoid arthritis for 33 years and SLE for 22 years, the patient was taking prednisone $\left(5 \mathrm{mg}^{-\mathrm{d}^{-1}}\right)$; had had an episode of acute myocardial infarction 20 years before with no sequelae; and was diagnosed with SLP for 18 years. Currently, she depends on nocturnal oxygen ( $2 \mathrm{~L}$. $\mathrm{min}^{-1}$ ) at home. She presented class II obesity, hypertension taking propranolol ( $80 \mathrm{mg}^{-\mathrm{d}^{-1}}$ ), and diabetes mellitus taking acarbose $\left(150 \mathrm{mg}^{-1} \mathrm{~d}^{-1}\right)$. She was also taking AAS (100 mg.d $\mathrm{d}^{-1}$ ), discontinued during the previous two weeks and atorvastatin $\left(20 \mathrm{mg}^{-1} \mathrm{~d}^{-1}\right)$. The patient reported dyspnea on mild exertion; being a former smoker for 15 years, while smoking 30 packs/year for 15 years. She underwent previous surgeries without anesthetic complications, except after left adrenalectomy when she presented difficult weaning from mechanical ventilation, requiring tracheostomy and ICU care for 9 days. 
At physical examination, the patient presented good general condition; was lucid and oriented, afebrile, acyanotic, anicteric, hydrated, and ruddy (weight $90 \mathrm{~kg}$, height $1.60 \mathrm{~m}$; $\mathrm{BMI}=35 \mathrm{~kg} \cdot \mathrm{m}^{-2}$ ).

Respiratory system showed universally audible breath sounds with rales at the right base of the hemithorax. Cardiovascular system showed a regular heart rhythm in two stages, with normal sounds and no murmurs; blood pressure of $110 \times 70 \mathrm{mmHg}$ and heart rate at $64 \mathrm{bpm}$. Abdomen was distended with hernial ring of $\pm 4 \mathrm{~cm}$ in the right supraumbilical region; airway Malampatti III; good oral opening $(4 \mathrm{~cm})$, with tracheostomy scar.

Blood count showed no changes. Arterial blood gas measurements were: $\mathrm{pH} 7.29 ; \mathrm{pCO}_{2} 45.2 \mathrm{mmHg} ; \mathrm{pO}_{2} 49.4 \mathrm{mmHg}$; $\mathrm{HCO}_{3}$ 20.4. Echocardiogram showed ejection fraction of $69 \%$ and holosystolic murmur of mitral regurgitation without systemic repercussions. Chest $\mathrm{X}$-ray showed right-sided diaphragmatic elevation (Figure 1). Chest tomography revealed subsegmental atelectasis in the middle and lower lobes of right lung, bilateral pleural thickening, elevated right hemidiaphragm, and pericardial thickening. Spirometry showed a severe restrictive ventilatory defect with moderate reduction of the alveolar-capillary oxygen diffusion. The patient was pre- viously evaluated by the cardiology and pulmonary teams and referred to the procedure. Physical status classification: ASA PS (P) III.

In the operating room, all airway material was prepared and tested, including the available laryngeal mask. After performing venous puncture, the patient was properly monitored with noninvasive blood pressure, oxygen saturation, electrocardiogram, and urinary catheter. Oxygen saturation was $94 \%$, but after using nasal cannula the oxygen saturation level was between $96 \%$ and $98 \%$. Midazolam $2.5 \mathrm{mg}$ and hydrocortisone $300 \mathrm{mg}$ were administered. For epidural anesthesia induction, the loss of resistance technique was used with median puncture at T10-T11 and infusion with a test dose of $3 \mathrm{~mL}$ of $2 \%$ lidocaine with vasoconstrictor, without hemodynamic effects. The epidural catheter was placed and then $15 \mathrm{~mL}$ of $0.75 \%$ ropivacaine and $50 \mu \mathrm{g}$ fentanyl were administered. Blood pressure was measured and an invasive arterial blood gas sample was collected. The surgery was uneventful, and the patient remained hemodynamically stable and adequately sedated.

At the end of surgery, which lasted three hours, a new epidural dose of $10 \mathrm{~mL} 0.125 \%$ ropivacaine with $2 \mathrm{~g}$ dipyrone and $8 \mathrm{mg}$ ondansetron was administered intravenously for post-
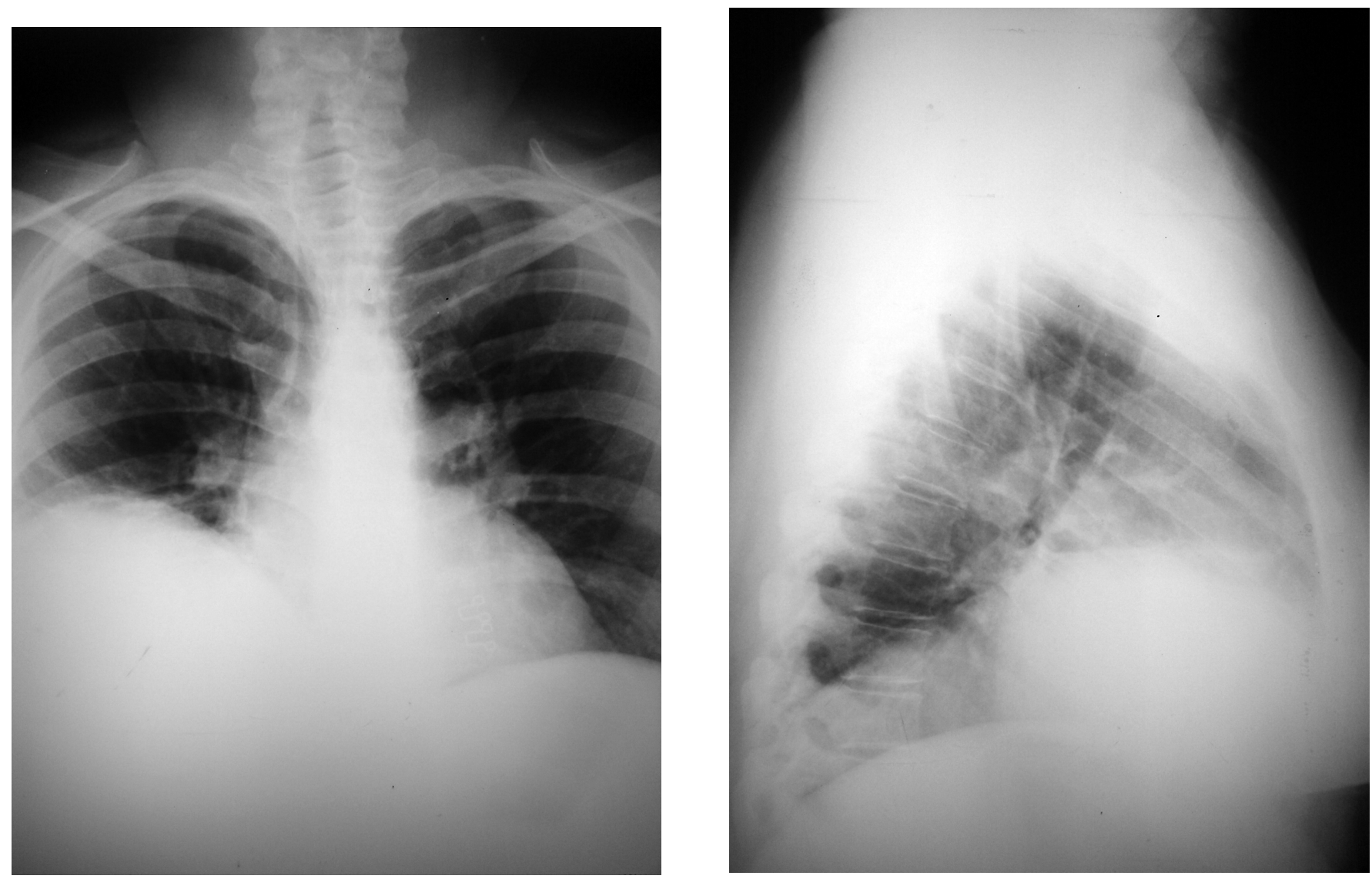

Figure 1 - Chest X-rays, Posteroanterior and Lateral Views, Showing Elevation of Right Hemidiaphragmatic Dome. 
operative analgesia and prevention of nausea and vomiting. Total urine output was $250 \mathrm{~mL}$. The patient was transferred to the Intensive Care Unit (ICU) hemodynamically stable, awake, lucid and cooperative, receiving oxygen by Venturi mask (10 L. $\mathrm{min}^{-1}$ ) and monitored. In the ICU, the patient remained without complaints, receiving dipyrone $2 \mathrm{~g}$ every 4 hours, without requiring other medications for pain or vomiting. She was discharged from ICU after 24 hours, transferred to the ward, and discharged from hospital on the third postoperative day.

\section{DISCUSSION}

The pathogenesis of SLS is controversial ${ }^{3,5}$. It has been suggested that there is a weakness of respiratory muscles, mainly diaphragmatic, due to a myopathy unrelated to corticosteroids ${ }^{5}$. This hypothesis is not always accepted by some researchers who suggest chest wall restriction as the main cause ${ }^{6}$. Most authors agree that SLS is a heterogeneous entity relating to multiple pathogenic processes ${ }^{5}$. The treatment remains empirical and involves the use of corticosteroids, immunosuppressive agents, xanthines, and inhaled beta-agonist (due to the positive inotropic effect of this substance on beta-receptors of diaphragmatic muscle) ${ }^{2-5,7}$. The prognosis is generally good, with improvement and stabilization of pulmonary symptoms. However, there is a report on death of a patient who remained dependent on mechanical ventilation, despite high doses of corticosteroids ${ }^{5}$.

The patient in this study had a restrictive pattern on spirometry and lung volumes reduced, without pleuropulmonary diseases justifying the dyspnea and oxygen. The epidural anesthesia was aimed at preventing early ministration of mechanical ventilation in this patient, allowing surgery under spontaneous breathing. The aim was also to avoid possible prolonged mechanical ventilation and to ensure adequate control of postoperative analgesia.
The decision on the choice of anesthesia is influenced by the surgical time and field, in addition to the patient's clinical conditions. The effects of epidural anesthesia on pulmonary function seem to be beneficial ${ }^{8,9}$. Both local anesthetics and opioids help diaphragmatic function, improving lung volume and capacity and reducing postoperative complications ${ }^{9,10}$. If the spread of local anesthetic reaches the cervical roots (C5 to $\mathrm{C} 3$ ), respiratory function may be compromised by blocking intercostal nerves and the partial or total blockage of the phrenic nerve. Changes in lung volumes and capacities after epidural block should not be forgotten because they directly alter the respiratory reserve.

Ropivacaine is a local anesthetic belonging to the pipecoloxylidide group, noted by the lower intensity of motor block and reduced potential for cardiovascular toxicity compared to bupivacaine ${ }^{8,9}$. It is known that the thoracic epidural block with concentrated solutions of bupivacaine causes a moderate reduction in vital capacity and in maximal inspiratory flow, probably due to a certain degree of relaxation of the intercostal muscles ${ }^{8,9}$. The use of less concentrated solutions of a local anesthetic such as ropivacaine may reduce the possibility of significant impairment of respiratory muscles ${ }^{9}$.

Considering the high incidence of hypotension and bradycardia resulting from blockade of sympathetic cardioacceleratory fibers, this technique should be performed with extreme caution. Proper selection of patients, accurate monitoring of vital functions, knowledge of the technique chosen and its physiological implications are of vital importance.

\section{CONCLUSION}

Shrinking lung syndrome is a rare disease which characteristics require the anesthesiologist's prior knowledge of the patient's clinical and laboratory history. This article has shown that thoracic epidural anesthesia was a good option for this patient, with highly satisfactory respiratory evolution. 


\section{REFERÊNCIAS/REFERENCES}

1. Hines RL, Marschall KE - Skin and Musculoskeletal Diseases em: Stoelting's Anesthesia and Co - Existing Diseases, Quinta Edição, Philadelphia, Elsevier Inc., 2008.

2. Oud KTM, Bresser P, ten Berge RJM et al. - The shrinking lung syndrome in systemic lupus erythematosus: improvement with corticosteroid therapy. Lupus, 2005;14:959-63.

3. Costa CA, Junior DOC, Jezler S et al. - Síndrome do pulmão encolhido no lúpus eritematoso sistêmico. J Bras Pneumol, 2004;30(3):26063.

4. Hoffbrand $\mathrm{BI}$, Beck ER - Unexplained dyspnoea and shrinking lungs in systemic lúpus erythematosis. Br Med J, 1965;5445:1273-1277.

5. Warrington KJ, Moder KG, Brutinel WM - The shrinking lung syndrome in systemic lupus erythematosus. Mayo Clin Proc, 2000;75:467-72.

6. Ernest $D$, Leung $A-$ Ventilatory failure in shrinking lung syndrome is associated with reduced chest compliance. Intern Med J, 2010;40: 66-79.

7. Toya SP, Tzelepis GE - Association of the shrinking lung syndrome in systemic lupus erythematosus with pleurisy: a systematic review. Semin Arthritis Rheum, 2008;38:30-37.

8. Novaes MVM, Francisco CRL, Pimenta KB et al. - Estudo comparativo entre bupivacaína a 0,25\% e ropivacaína a 0,2\% em anestesia peridural para cirurgia torácica. Rev Bras Anestesiol, 2001;51(6):493502.

9. Nociti JR, Serzedo PSM, Zuccolotto EB et al. - Ropivacaína em bloqueio peridural torácico para cirurgia plástica. Rev Bras Anestesiol, 2002;52(2):156-165

10. Leao DG - Peridural torácica: estudo retrospectivo de 1240 casos. Rev Bras Anestesiol, 1997;47(2):138-147. 